\title{
Performance Characteristics of Magnetic Abrasive Finishing (MAF) of Al 4061
}

\author{
Vasantha Prasath N \\ Assistant Professor, Department of Mechanical \\ Engineering \\ GRT Institute of Engineering and Technology \\ Tiruttani-631209, Tiruvallur, India
}

\author{
Abdul Gaffar T , \\ PG Student, Department of Mechanical Engineering \\ GRT Institute of Engineering and Technology \\ Tiruttani-631209, Tiruvallur, India
}

\author{
Vasanth A \\ Assistant Professor, Department of Mechanical Engineering \\ GRT Institute of Engineering and Technology \\ Tiruttani-631209, Tiruvallur, India
}

\begin{abstract}
Magnetic abrasive finishing (MAF) is one of the most important final machining processes, and the performances of finishing media play an important role in the finishing effects and efficiency. In this paper, a new magnetic finishing media with semi-solid state was presented and prepared, and finishing setup for the outer rotary surface was developed. In order to determine the optimum angle between $\mathrm{N}$ pole and $S$ pole, simulation was performed using ANSYS Maxwell 14.0. MRR as a function of magnetic flux density, mass ratio, rotational speed of magnetic poles and diameter of abrasive particles and ferromagnetic particles. Finishing experiments of main parameters on materials removal ratio MRR was examined. Experimental results indicated that the percentage change $\%$ in the material removal and surface roughness amount increased with the increase of the rotational speed, the mesh number of the abrasive particles, and the mass ratio of base polymer, ferromagnetic phase and abrasive phase.
\end{abstract}

Keywords-Magnetic Abrasive Finishing; Orthogonal Array

\section{INTRODUCTION}

Magnetic abrasive finishing (MAF) is one of the advanced finishing processes, which produces a high level of surface quality and is primarily controlled by a magnetic field. In MAF, the work piece is kept between the two poles of a magnet. The working gap between the work piece and the magnet is filled with magnetic abrasive particles. A magnetic abrasive flexible brush (MAFB) is formed, acting as a multipoint cutting tool, due to the effect of the magnetic field in the working gap. When inserting a cylindrical work piece in such a processing field giving revolution, feed and vibration in axial direction, surface and edge finishing are carried out by magnetic brush. In the application of ferromagnetic substance of work, for instance, work piece is also magnetized and the magnetic force acts on the top of the brush between the work piece and the abrasive grains resulting in pressing the abrasive grains to work surface. The MAF process removes a very small amount of material by indentation and rotation of magnetic abrasive particles in the circular tracks. High quality and limited dimensional tolerance parts used in the aircraft, automobile, and shipbuilding industries require excellent surface finish. Conventional methods such as filling, lapping, honing, super finishing, grinding, polishing and buffing are used to modify the surface texture produced by manufacturing process. To further optimize the finishing operation unconventional machining processes like MAM are gaining attention owing to their ability to provide better surface finish than the conventional processes. Magnetic abrasive machining (MAM) is a process in which a magnetic power is employed as a machining force. This force is directing the abrasive particles towards the target surface. The efficiency of the process is easily controllable by the electric current. To prevent the over-finishing of surface roughness, careful monitoring of the process automation is needed. Therefore, MAM has been used for accuracy of surface finishing because of many advantages such as self-adaptability, controllability and self-sharpening.

Various industrial applications require very high surface finish up to the range of nanometres or even above with the development of modern manufacturing trends. Presently, it is required that the parts, used in manufacturing semiconductors, atomic energy parts, medical instruments and aerospace applications, have a very fine surface roughness. Amongst them, vacuum tubes, wave-guides and sanitary tubes are difficult to be polished by conventional finishing methods such as lapping, because of their shapes. The technology for super finishing needs ultra clean machining of advanced engineering materials such as silicon nitride, silicon carbide, and aluminium oxide which are used in high- technology industries and are difficult to finish by conventional grinding and polishing techniques with high accuracy, and minimal surface defects, such as micro cracks. Therefore, magnetic abrasive finishing (MAF) process has been recently developed for efficient and precision finishing.

With the development of high-end equipment, there are a large number of components having high performance, which require good surface layer structure, high surface quality, mechanical and physical properties. Their surface quality directly affects the service performance and service life of the equipment. For example, the surface quality of the very low friction hydraulic valve spool and valve sleeve has a direct impact on assembly quality, sealing and service performance.

Magnetic abrasive finishing (MAF) is one of the nontraditional machining processes, which can realize the decrease of surface roughness value and improvement of wear 
resistance and mechanical properties by interaction and relative motion between the media and the work piece. MAF has been used to finish solid or hollow cylindrical parts and flat workpieces and it was investigated from finishing mechanism, process parameters, material removal and surface integrity by many researches and reported the internal finishing of stainless steel tubes and determined the finishing effects. Reported the development of a typical internal finishing process by applying magnetic abrasives using a pole rotation system and investigated the finishing process for alumina ceramic components and austenitic stainless steel capillary tubes investigated the ultra-precision finishing of the inner surface of ceramic tube using MAF. Explored the application of low frequency alternating magnetic field for imparting surface modification of brass tube. Developed a setup used for finishing Para/diamagnetic flat workpieces with different hardness values and compared the finishing characteristics of two paramagnetic materials.

Developed a mathematic model of surface roughness $\mathrm{Ra}$ as a function of work piece material properties and process factors. Proposed a new ultra-precision MAF process using low frequency alternating magnetic field and investigated the effects of alternating magnetic field on magnetic field distribution, finishing force and abrasive behavior. Explored a pulsating direct current to the electromagnet to create a stirring effect on the flexible magnetic abrasive brush, and reported an obvious improvement in surface roughness over the conventional processes in which a static direct current was applied to the electromagnet. Developed a novel tool based on MAF principle for finishing holes, blind holes, grooves and vertical surfaces, and evaluated the finishing performance by experimental study. Investigated the inter-relations of key finishing parameters by using a dual magnetic roller tool and a 6-axis robot arm the influence of three vibration modes on the polishing effectiveness and studied the effect of types and size of abrasive on surface finishing reported ultrasonic assisted magnetic abrasive finishing.

(U MAF) and measured the machining forces in case of MAF and UAMAF. Reported UAMAF and discussed material removal mechanism, then developing a mathematical model predicting the material removal ratio (MRR). Reported a new media based on viscoelastic carrier and investigated the improvement of surface roughness Ra for finishing aluminum workpieces. The maximum improvement in surface roughness $\mathrm{Ra}$ is $23 \%$ investigated the effects of some parameters on surface roughness Ra for aluminum sheet with MAF, and the maximum decrease value $\mathrm{Ra}$ in surface roughness $\mathrm{Ra}$ is 0.267 reported the development of new vibration assisted cylindrical-magnetic abrasive finishing (VAC-MAF) setup. The material removal and the decrease of surface roughness $\mathrm{Ra}$ for improved approximately by $100 \%$ and $150 \%$, respectively, as compared to MAF without vibration. A hybrid process combining electrochemical machining and MAF, which was used to process $\mathrm{Al}$ 6061. The surface roughness Ra decreased from $1.3 \mu \mathrm{m}$ to $0.2 \mu \mathrm{m}$. Developed a new MAF setup for finishing internal spiral grooves of a cylindrical tube and analyzed the finishing mechanism. the effect of the process parameters on surface roughness $\mathrm{Ra}$ for aluminum specimen was investigated, and microscopic surface profiles demonstrate $70 \%$ improvement in the surface roughness Ra. All the studies focus on finishing mechanism, process parameters, the magnetic field improvement, finishing effects and hybrid process. The literatures about the property improvement of the media were rarely reported.

In MAF, finishing media used at present are almost powder media. This kind of finishing media is easy to escape from the finishing zone, and its availability is extremely low.

In view of the above, in this study, we prepared a kind of magnetic finishing media which has viscoelastic characteristics, that is, the deformation properties of this media have the characteristics of both solid elasticity and liquid viscosity under the action of external force, and its mechanical properties change with time, called as the mechanical relaxation phenomenon. The new finishing media show semi-solid state, having good magnetic conductivity and fluidity, and this resilient multipoint cutting tool has the flexibility to deform itself in conformity to the shape of workpiece surface and can be used to remove materials from complicated geometries.

\section{EXPERIMENTAL SET UP}

\section{A. Design of NdFeb Magnetic Holding Fixture}

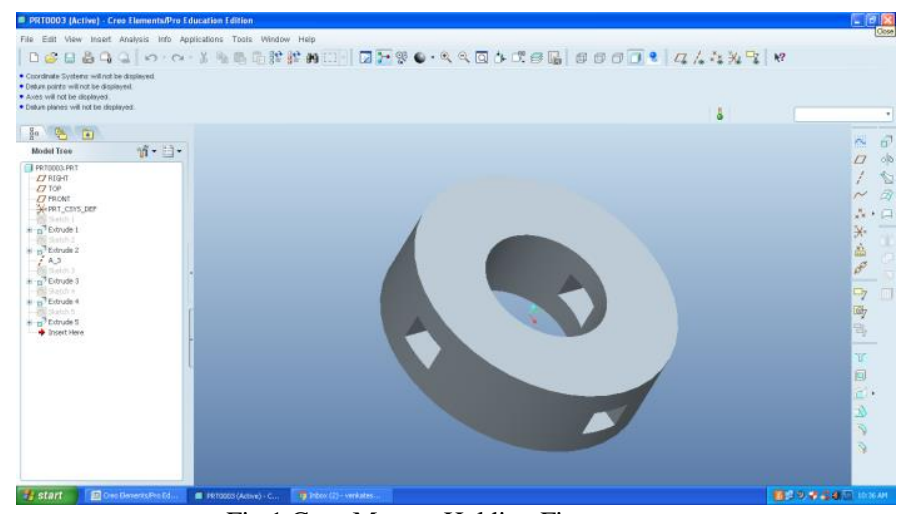

Fig 1 Creo-Magnet Holding Fixture

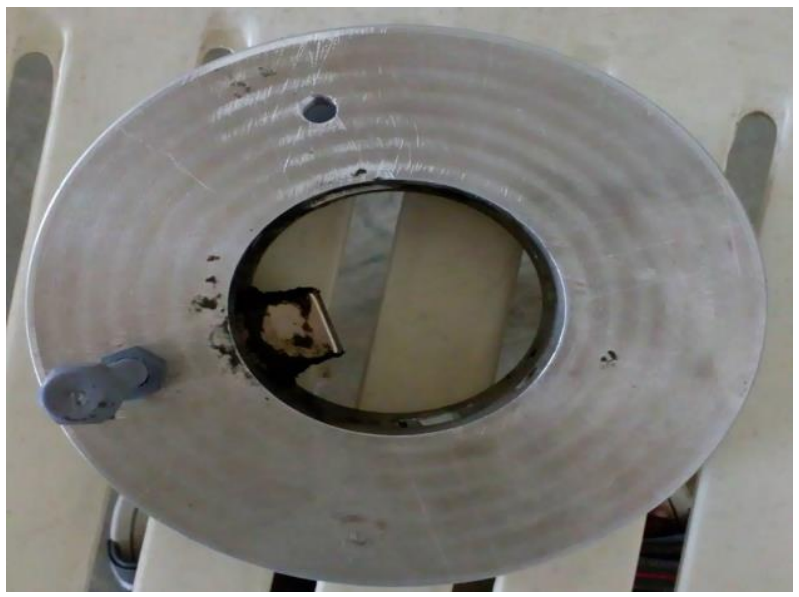

Fig.2. Fabricated Magnet Work Holding Device 


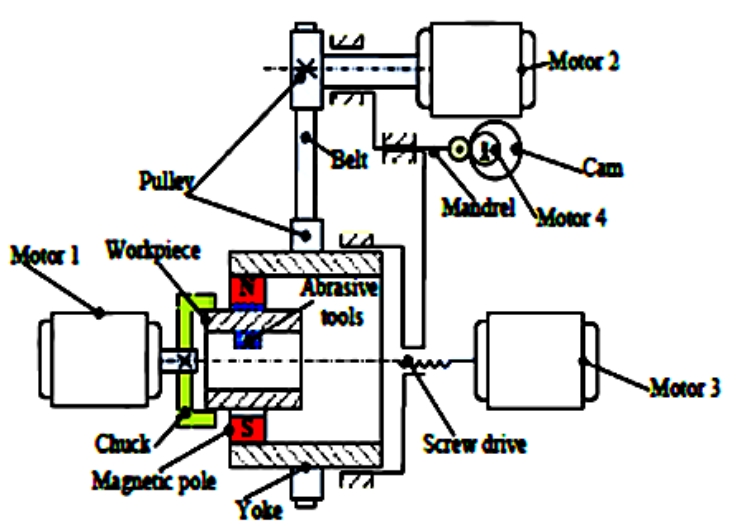

Fig.3 Experimental Setup

The setup includes four motors, belt drive, magnetic field generator, cam mechanism, screw mechanism and automatic control system. Motor 1 drives the workpiece rotating. The magnetic field generator is composed of $\mathrm{NdFeB}$ magnets (that is magnetic poles) and yoke, and $\mathrm{NdFeB}$ permanent magnets are mounted on the yoke. The number and the radial or circumferential position of magnets can be changed in order to alter magnetic flux density. Motor 2 drives the magnetic field generator rotating by the belt drive. Motor 3 drives the magnetic field generator moving along the axial direction of the workpiece by screw mechanism. Motor 4 drives the magnetic poles realizing vibrations along the axial direction of the workpiece by cam mechanism. When the media are placed in the inner surface of the workpiece or the gap between the workpiece and magnetic poles, they would attach to the workpiece surface due to the action of the strong magnetic force. When the magnets and/or the workpiece move, surface finishing of the workpiece would be achieved.

Table 1 Details of Simulation

\begin{tabular}{|l|l|}
\hline Factors & Magnitude \\
\hline Shape of magnetic poles & Rectangular Shaped \\
\hline Inner diameter of magnetic poles & $50 \mathrm{~mm}$ \\
\hline Outer diameter of magnetic poles & $150 \mathrm{~mm}$ \\
\hline Thickness of magnetic poles & $10 \mathrm{~mm}$ \\
\hline Material of magnetic poles & $\mathrm{N} 40 \mathrm{NdFeB}$ \\
\hline Angle $\theta$ between N pole and S pole & $90^{\circ}$ \\
\hline Diameter of workpiece & $25 \mathrm{~mm}$ \\
\hline Length of workpiece & $120 \mathrm{~mm}$ \\
\hline Material of workpiece & 4061 Aluminium alloy \\
\hline
\end{tabular}

Table 2 Properties of $\mathrm{N} 40 \mathrm{NdFeB}$ permanent magnetic poles

\begin{tabular}{|l|l|l|l|l|}
\hline $\begin{array}{l}\text { Remanence } \\
\text { strength }\end{array}$ & $\begin{array}{l}\text { Coercive } \\
\text { force }\end{array}$ & $\begin{array}{l}\text { Intrinsic } \\
\text { coercivity }\end{array}$ & $\begin{array}{l}\text { Maximum } \\
\text { energy } \\
\text { product }\end{array}$ & $\begin{array}{l}\text { Maximum } \\
\text { operating } \\
\text { temperature }\end{array}$ \\
\hline $\mathrm{mT}$ & $\mathrm{kA} / \mathrm{m}$ & $\mathrm{kA} / \mathrm{m}$ & $\mathrm{kJ} / \mathrm{m} 3$ & ${ }^{\circ} \mathrm{C}$ \\
\hline $1250-1280$ & $\geq 923$ & $\geq 955$ & $\geq 318-342$ & 80 \\
\hline
\end{tabular}

Table 3 Details of experimental conditions

\begin{tabular}{|l|l|}
\hline Factors & Magnitude \\
\hline Workpiece hardness & $80 \mathrm{HB}$ \\
\hline Density of workpiece & $2.8 \mathrm{~g} / \mathrm{cm} 3$ \\
\hline Diameter of abrasive particle & $0.048 \mathrm{~mm}$ \\
\hline Diameter of ferromagnetic particle & $0.15 \mathrm{~mm}$ \\
\hline Thickness of magnetic poles & $10 \mathrm{~mm}$ \\
\hline Relative permeability of abrasive particle & 0.999996 \\
\hline $\begin{array}{l}\text { Relative permeability of ferromagnetic } \\
\text { particle }\end{array}$ & 1350 \\
\hline Relative permeability $\mu 0$ & $4 \times 10-7 \mathrm{H} / \mathrm{m}$ \\
\hline Magnetic flux intensity B & $0.45 \mathrm{~T}$ \\
\hline Rotational speed of magnetic poles & $346,516,792$ \\
\hline
\end{tabular}

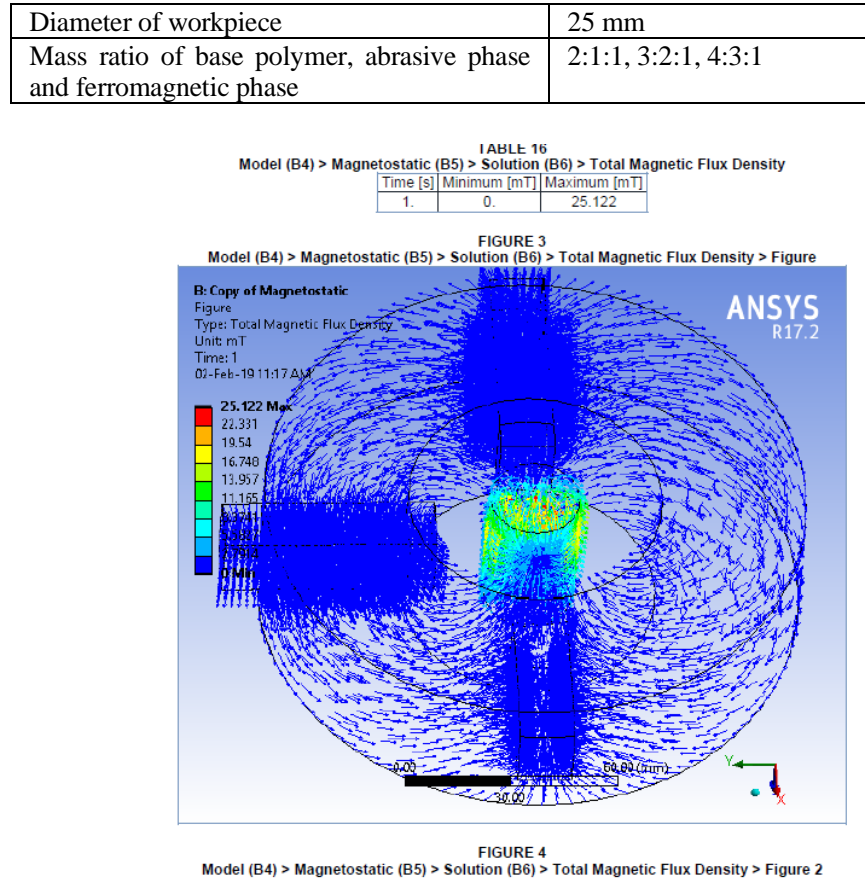

Fig.3. Ansys total magnetic flux density

\section{EXPERIMENTAL RESULTS AND DISCUSSION}

The Table 4 shows the machining parameters such as Rotation of Magnetic Poles, Mass Ratio, Abrasive mesh size and their levels for the machining $\mathrm{Al} 4061$.

Table 4 Machining Parameters and their levels

\begin{tabular}{|c|c|c|c|c|}
\hline S.No & Control Parameters & L1 & L2 & L3 \\
\hline 1 & Mass Ratio & $2: 1: 1$ & $3: 2: 1$ & $4: 3: 1$ \\
\hline 2 & $\begin{array}{c}\text { Rotation of Magnetic } \\
\text { Poles (rpm) }\end{array}$ & 346 & 516 & 792 \\
\hline 3 & $\begin{array}{c}\text { Abrasive Mesh size } \\
\text { (Sic, Grit) }\end{array}$ & 100 & 200 & 225 \\
\hline
\end{tabular}

\section{A. Degress of freedom}

The number of comparisons that needs to be made to determine which level is better. For example, a four level parameter has three degree of freedom. The Orthogonal array is selected based on the degrees of freedom.

\section{B. Selection of Orthogonal Array}

Calculated degrees of freedom $=6<9$ and which is closer to L9.So, for the present analysis, an L9 orthogonal array with three columns and nine rows is used. Only nine experiments are required to study the entire machining parameters using the $\mathrm{L}_{9}$ orthogonal array.

\section{L9 Orthogonal Array}

Calculated degrees of freedom is 9 and which is closer to $\mathrm{L}_{9}$. So, for the present analysis, an $\mathrm{L}_{9}$ orthogonal array with three columns and nine rows is used which is shown in Table 5 .

Table 5 L9 Orthogonal array

\begin{tabular}{|c|c|c|c|}
\hline S.No & Mass Ratio & $\begin{array}{c}\text { Rotation of } \\
\text { Magnetic } \\
\text { Poles (rpm) }\end{array}$ & $\begin{array}{c}\text { Abrasive } \\
\text { Mesh Size }\end{array}$ \\
\hline 1 & 1 & 1 & 1 \\
\hline 2 & 1 & 2 & 2 \\
\hline 3 & 1 & 3 & 3 \\
\hline 4 & 2 & 1 & 2 \\
\hline
\end{tabular}




\begin{tabular}{|l|l|l|l|}
\hline 5 & 2 & 2 & 3 \\
\hline 6 & 2 & 3 & 1 \\
\hline 7 & 3 & 1 & 3 \\
\hline 8 & 3 & 2 & 1 \\
\hline 9 & 3 & 3 & 2 \\
\hline
\end{tabular}

Table 6 shows the orthogonal array with values such as Rotation of Magnetic Poles, Mass Ratio, Abrasive mesh size for conducting the experiments on Magnetic Abrasive Machining.

Table $6 \mathrm{~L}_{9}$ Orthogonal Array with Values

\begin{tabular}{|c|c|c|c|}
\hline S.No & Mass Ratio & $\begin{array}{c}\text { Rotation of } \\
\text { Magnetic Poles } \\
(\mathrm{rpm})\end{array}$ & $\begin{array}{c}\text { Abrasive Mesh } \\
\text { Size }\end{array}$ \\
\hline 1 & $2: 1: 1$ & 346 & 100 \\
\hline 2 & $2: 1: 1$ & 516 & 200 \\
\hline 3 & $2: 1: 1$ & 792 & 225 \\
\hline 4 & $3: 2: 1$ & 346 & 200 \\
\hline 5 & $3: 2: 1$ & 516 & 225 \\
\hline 6 & $3: 2: 1$ & 792 & 100 \\
\hline 7 & $4: 3: 1$ & 346 & 225 \\
\hline 8 & $4: 3: 1$ & 516 & 100 \\
\hline 9 & $4: 3: 1$ & 792 & 200 \\
\hline
\end{tabular}

The experimental observations are planned in such a way for conducting fruitful research analysis for deriving the effective research findings, which could be useful to the applied researchers and manufacturing industries in the area of micromachining achieved through MAF. To analyze the control of the desired performance characteristics of the process parameters of the Magnetic Abrasive Finishing system, a scheme was designed so as to properly utilize the developed MAF set-up.

All the experiments were carried out on 4061 aluminum alloy. The amount of the media is was $40 \mathrm{~g}$. The diameter of all the workpiece was $25 \mathrm{~mm}$ so that the samples could keep suitable gap with the magnetic poles. For experimentation, the workpiece was held rigidly on the experimental setup with the help of three jaw chuck.

Initial and final weights of the jobs were taken by a precision electronic weighing machine. MRR was calculated as the material removed, i.e. the difference of initial and final weight per unit machining time. The standard machining time for each experiment is $30 \mathrm{~min}$.

\section{Experimental results for MRR and surface roughness}

Table 6 Experimental Results of MRR

\begin{tabular}{|c|c|c|c|c|}
\hline \multirow{2}{*}{ S.No } & \multicolumn{2}{|c|}{ MRR (gm) } & $\begin{array}{c}\text { MRR } \\
(\mathrm{gm})\end{array}$ & MRR \\
\cline { 2 - 5 } & $\begin{array}{c}\text { Before } \\
\text { Machining }\end{array}$ & $\begin{array}{c}\text { After } \\
\text { Machining }\end{array}$ & Diff & $\begin{array}{c}\mathrm{mm}^{3} / \mathrm{min} \\
\left(10^{-6}\right)\end{array}$ \\
\hline 1 & 142.740 & 142.708 & 0.032 & 1.067 \\
\hline 2 & 139.602 & 139.515 & 0.087 & 2.9 \\
\hline 3 & 142.936 & 142.104 & 0.832 & 0.277 \\
\hline 4 & 140.927 & 140.899 & 0.028 & 93.33 \\
\hline 5 & 141.768 & 141.386 & 0.382 & 0.127 \\
\hline 6 & 141.976 & 141.137 & 0.839 & 0.279 \\
\hline 7 & 140.637 & 140.601 & 0.036 & 1.2 \\
\hline 8 & 142.952 & 142.893 & 0.059 & 1.97 \\
\hline 9 & 142.033 & 140.955 & 1.078 & 0.359 \\
\hline
\end{tabular}

Table 7 Experimental Results of Surface Roughness

\begin{tabular}{|c|c|}
\hline S.No & Surface Rougness $\left(\mathrm{R}_{\mathrm{a},} \mu \mathrm{m}\right)$ \\
\hline 1 & 0.65 \\
\hline 2 & 1.83 \\
\hline 3 & 1.63 \\
\hline 4 & 1.08 \\
\hline 5 & 0.8 \\
\hline 6 & 1.09 \\
\hline 7 & 1.69 \\
\hline 8 & 1.54 \\
\hline 9 & 1.4 \\
\hline
\end{tabular}

\section{OPTIMIZATION}

In order to assess the effect of each machining parameters on the Process ,the Taguchi approach was used.This method is a type of Statistical technique called Design of Experiments (DOE) that makes it possible to analyze the effect of more than one factor at the same time while reducing the number of experiments. Thus using the Taguchi approach, the design of experiments and analysis of results can be done with less effort and expenses. However, since the method considerably reduces the number of experiments, quality loss of results could appear.

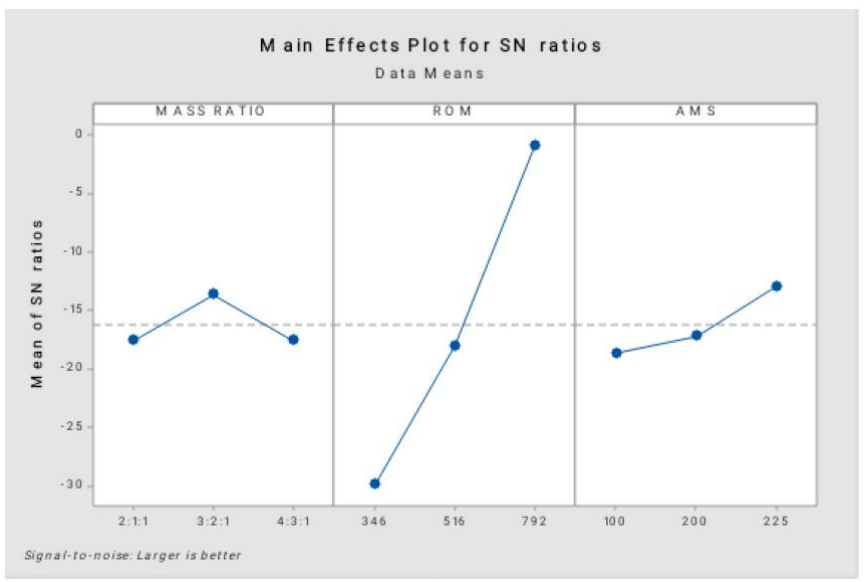

Fig.4. S/N ratio of MRR

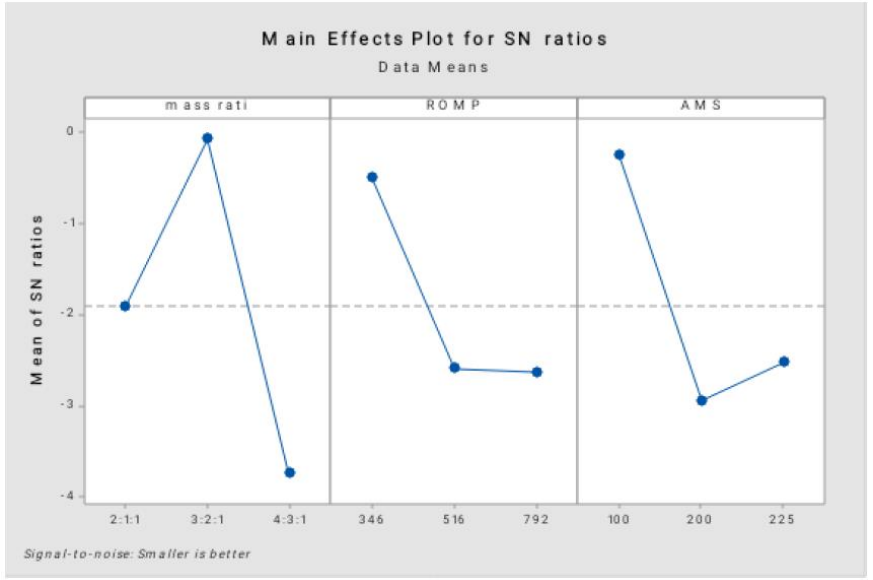

Fig.5. S/N ratio of Ra

The best machining condition to achieve better MRR \& Lower Surface roughness is 3:2:1, $792 \mathrm{rpm}, 225 \mu \mathrm{m} \& 4: 3: 1$, $792 \mathrm{rpm}, 200 \mu \mathrm{m}$. 


\section{CONCLUSION}

This paper presents a newly developed media and its material removal model. The main conclusions are deduced as follows:

The magnetic flux density increases first and then decreases with the increase of the angle between $\mathrm{N}$ pole and $\mathrm{S}$ pole. When the angle is $90^{\circ}$, the magnetic flux density is the maximum and finishing capacity of the media is high. Therefore, the optimum angle between $\mathrm{N}$ pole and $\mathrm{S}$ pole is $90^{\circ}$.It is established theoretically that the MRR is a function of the rotational speed, the mass ratio and the mesh number of abrasive particles. The MRR model is validated by the experiment.With the increase of the rotational speed and the mesh number of abrasive particles, the \% Ra and the MRA increased. With the mass ratio of base polymer, ferromagnetic phase and abrasive phase is $4: 3: 1$, the \% Ra reaches the maximum of $94.85 \%$, and the MRR reaches the maximum of $1.85 \mathrm{mg} / \mathrm{s}$. This finishing process could not only be used to finishing the outer surface or inner surface of small tube, but also be used to finishing large tube and special components such as deep groove and narrow slit by adjusting the size and position of the magnetic poles. However, this process has a certain limitation being used to finish blind hole due to small force.The roughness and tolerance band of component achieved using control parameter Magnetic Abrasive Machining (MAM) for polishing of cylinder work piece was developed using available abrasives.

The experimentation with these process parameters reduced the surface roughness value on a cylindrical component from an initial $\mathrm{Ra}$ value. These studies also indicated the need to consider the work piece initial roughness, apart from its hardnessfor achieving an improved finish on the work surface. Study shows that on various parameters improvement insurface finish is maximum in case of brass as compared to other materials.

\section{REFERENCES}

[1] Amnieh, S.K., Mosaddegh, P., Tehrani, A.F., 2017, "Study on magnetic abrasive finishing of spiral grooves inside of aluminum cylinders”. Int. J. Adv. Manuf. Technol. 91, 2885-2894.

[2] Archard, J., 1953, “Contact and rubbing of flat surfaces". J. Appl. Phys. 24(8), 981-988.

[3] M., Agrawal, K., Shinmura, T., Komanduri, ., 1994, "Magnetic abrasive finishing of rollers", CIRP Ann-Manuf. Technol. 43(1), 181-184.

[4] Givi, M., Tehrani, A.F., Mohammadi, A., 2012, "Polishing of the aluminum sheets with magnetic abrasive finishing method", Int. J. Adv. Manuf. Technol. 61, 989-998.

[5] Guo, D.M., Sun, Y.W., Jia, Z.Y., 2014, "Methods and research progress of high performance manufacturing", J. Mech. Eng. 50(11), 119-134.

[6] Guo, J., Tan, Z.E., Au, K.H., Liu, K., 201, “ Experimental investigation Intothe effect of abrasive and force conditions in magnetic field-assisted finishing", Int. J. Adv. Manuf. Technolology, 90, 1881-1888.

[7] Jain,V.K.,Singh,D.K.,Raghuram,V., 2008, “Analysis of performance of pulsating flexible magnetic abrasive brush (PFMAB)", Mach. Sci. Technol. 12(1), 53-76.

[8] Judal, K.B., Yadava, V., Pathak, D., 2013, "Experimental investigation of vibration assisted cylindrical-magnetic abrasive finishing of aluminum workpiece", Mater. Manuf. Process. 28(11), 1196-1202.

[9] Kala, P., Pandey, P.M., 2015, "Comparison of finishing characteristics of two paramagnetic materials using double disc magnetic abrasive finishing”, J. Manuf. Process. 17, 63-77.
[10] Kala, ., Sharma, V., Pandey, P.M., 2017., "Surface roughness modelling for double disk magnetic abrasive finishing process", J. Manuf. Process. 25, 37-48.

[11] Kumar, H., Singh, S., Srivastava, A., 2016, "Parametric investigations into internal surface modification of brass tubes with alternating magnetic field", Procedia Manuf. 5, 1234-1248.

[12] Kurore, T., Imanaka, O., Tachibana, S., 1983, "Magnetic fieldassisted fine finishing", Bull. Japan Soc. Prec. Eng. 17(1),49-50.

[13] Li, W.H., Li, X.H., 2012, "Technique project and experimental study of viscoelastic magnetic abrasive finishing", Adv. Sci. Lett. 12(1), 30-33.

[14] Li, W.H., Li, X.H., Yang, S.Q., 2015, "Parameter influence on interfacial stress of a new composite material for surface finishing", Mater. Res. Innov. 43, 657-664

[15] Li, W.H., Yang, S.Q., Li, X.H., Zhai, H.F., Shi, J, 2013 , "Mechanism research and experimental study of viscoelastic magnetic abrasive tools finishing", J. Chem. Pharm. Res. 15, 278-285

[16] Li, X.H., Li, W.H., Yang, S.Q., 2016, "Effect of coupling agent on interfacial bonding properties of viscoelastic magnetic abrasive tools and finishing performance", Int. J. Simul-Sys. Sci. Technol. 17(28), 17.1- 17.8.

[17] Liu,G.Y.,Guo,Z.N.,Jiang,S.Z.,Qu, N.S., Li, Y.B., 2014, “A study of processing $\mathrm{Al} 6061$ with electrochemical magnetic abrasive finishing", 6th CIRP International Conference on High Performance Cutting. 234-238. 